Fatemeh Gholipour ${ }^{1}$, Mohammad Rahmani ${ }^{2, \star}$ and Farhad Panahi ${ }^{1}$

\title{
Efficient and selective microwave-assisted 0-methylation of phenolic compounds using tetramethylammonium hydroxide (TMAH)
}

https://doi.org/10.1515/gps-2019-0028

Received October 12, 2018; accepted March 11, 2019.

\begin{abstract}
In this study, an efficient method for O-methylation of phenolic compound using tetramethylammonium hydroxide (TMAOH) as a new alkylating agent under microwave irradiation was developed. Ethanol was selected as a green reaction media to accomplish this protocol under environmentallybenign conditions. Less than half hour time is needed to obtain good to excellent yields of products at temperature of about $120^{\circ} \mathrm{C}$. Using this procedure, phenolic compounds could be converted to the corresponding aryl methyl derivatives quickly. The results indicated that different phenolic compounds bearing both electron-withdrawing and electron-donating groups are O-methylated effectively using TMAOH under microwave irradiation. This novel protocol has many improvements in view point of reaction yields, selectivity and conditions compared to previous studies. Trimethylamine and water were the side products of $\mathrm{O}$-methylation reaction which can be recovered easily from the product mixture. This methodology showed high selectivity for O-methylation and no C-methylated products were observed.
\end{abstract}

Keywords: microwave-assisted; O-methylation; phenolic compound; tetramethylammonium hydroxide

\section{Introduction}

O-Methylation of phenolic compounds is an important strategy in organic chemistry due to its high applicability in synthesis of many petrochemicals, fine chemicals, pharmaceuticals, fragrances, dyes and agrochemicals [1].

\footnotetext{
* Corresponding author: Mohammad Rahmani, Department of Chemical Engineering, Amirkabir University of Technology (Tehran Polytechnic), Tehran, 15875-4413, Iran, Tel.: +9821-64543198, e-mail: m.rahmani@aut.ac.ir

Fatemeh Gholipour and Farhad Panahi, Department of Chemical Engineering, Amirkabir University of Technology, Mahshahr, Iran
}

There are several reports in the literature on the synthesis of methyl aryl ethers using methylation of phenolic compounds (Figure 1).

In traditional methods toxic methylating agents such as methyl iodide [2,3] methyl bromide [3], dimethyl sulfate1 [4-6] and diazomethane [7] have been used. Methyl halides are toxic gaseous materials because they can methylate nucleic acids in living organisms [8]. To use dimethyl sulfate as alkylating agent stoichiometric amount of strong base for neutralization of acidic by-products is required [4,5]. Due to the growing awareness of environmental issues, the commercial application of these material are restricted. In order to avoid the use of mentioned methylating agents other methods have been developed. The O-methylation of phenol with methanol in the presence of a strong acid has been widely investigated [9-13]. This method is an acid catalyzed process and the product selectivity depends on properties of the used acid catalyst. In most cases, the conversions of phenols are not satisfactory and the C-methylation is the competition reaction and a large amount of byproduct is produced which complicated the workup and purification process. A clean, and selective methylation protocols was developed using dimethyl carbonate as a less-toxic reagent $[14,15]$. The reaction of phenol with dimethyl carbonate was also carried out under gas/liquid phase transfer catalysis conditions in the presence of $\mathrm{K}_{2} \mathrm{CO}_{3}$ coated with polyethylene glycol $[16,17]$. Using this reagent, anisole was obtained in high yields along with a high selectivity. However this reagent has serious limitations to be used for high boiling point phenols [18]. The vapor phase methylation of phenol with dimethyl carbonate was also performed over ion-exchanged zeolites in the continuousflow conditions [19-22]. However, this reaction is carried out at high temperature and two byproducts including $o$-cresol and 2,6-xylenol are produced beside to anisole.

In this situation, methylation of both phenol and $p$-cresol using dimethyl carbonate were performed in a continuously fed stirred tank reactor [18]. The O-methylation of phenol with dimethyl carbonate has also been reported over 1-butyl-3-methylimidazolium 
chloride [23,24], potassium carbonate [25], magnesium oxide [26], Mg-Al mixed oxides [27]. Unfortunately, in all of the mentioned methods for methylation using dimethyl carbonate, C-alkylation by-products are always detected. Trimethylsulfonium salts was also used for methylation of phenols [28]. This reaction is carried out in the presence of methanol and potassium carbonate while the conversion was not satisfactory. In this situation, quaternary amines such as phenyltrimethylammonium salts was employed for O-methylation of phenolic compounds in alkaloids chemistry [29]. For example, phenyltrimethylammonium chloride, in the presence of potassium carbonate in dry dimethylformamide (DMF) afforded glaucine from its starting material in good yield [30]. The $O$-methylation of phenols with trimethylammonium acetate was occurred at temperature of $200-230^{\circ} \mathrm{C}$ and use of $\mathrm{CaO}$ as a base [31]. Tetramethylammonium chloride is also reported to be used as a methylating agent for the methylation of phenols in the presence of $\mathrm{K}_{2} \mathrm{CO}_{3}$ or $\mathrm{Cs}_{2} \mathrm{CO}_{3}$ as base and dimethoxymethane as a solvent at $145^{\circ} \mathrm{C}$ under microwave conditions [29]. Other reagents used for O-methylation of phenols under microwave conditions are trimethylphosphit and trimethyl phosphate [32].

Herein we report a green and fast process for O-methylation of phenolic compounds using tetramethylammonium hydroxide (TMAH) in ethanol as green solvent at $120^{\circ} \mathrm{C}$ under microwave conditions without using base (Figure 1). Using our procedure the
O-methylation of phenolic compounds was achieved under more environmental conditions without using stoichiometric amount of base and using TMAOH as an abundant available and cheap methylating agent.

\section{Experimental}

\subsection{General}

All phenols and naphthols and tetramethylammonium hydroxide were commercially available and purchased from Merck and Aldrich chemical companies. Tetramethylammonium hydroxide is $25 \%$ solution in water. All products were known and their spectroscopic data were compared with those of authentic compounds. Analyses of the products were done on a GC-MS (Agilent 6890 N-GC-5973 N-MSD chromatograph, using a $30 \mathrm{~m} \times 0.25 \mathrm{~mm}$ Restek, Rtx-5SILMS column with a film layer of $0.25 \mu \mathrm{m}$. The initial temperature of column was $50^{\circ} \mathrm{C}$ for $1 \mathrm{~min}$, followed by programming at $10^{\circ} \mathrm{C} / \mathrm{min}$ up to $290^{\circ} \mathrm{C}$ and a final period at $290^{\circ} \mathrm{C}$ for $24 \mathrm{~min}$. The temperature of the injector was $250^{\circ} \mathrm{C}$. The carrier gas was helium and the operation mode was split100). Apart from the unconverted reactant 2-naphthol, the products were 2-methoxynaphthalene, and traces of 1-methyl-2methoxynaphthalene.

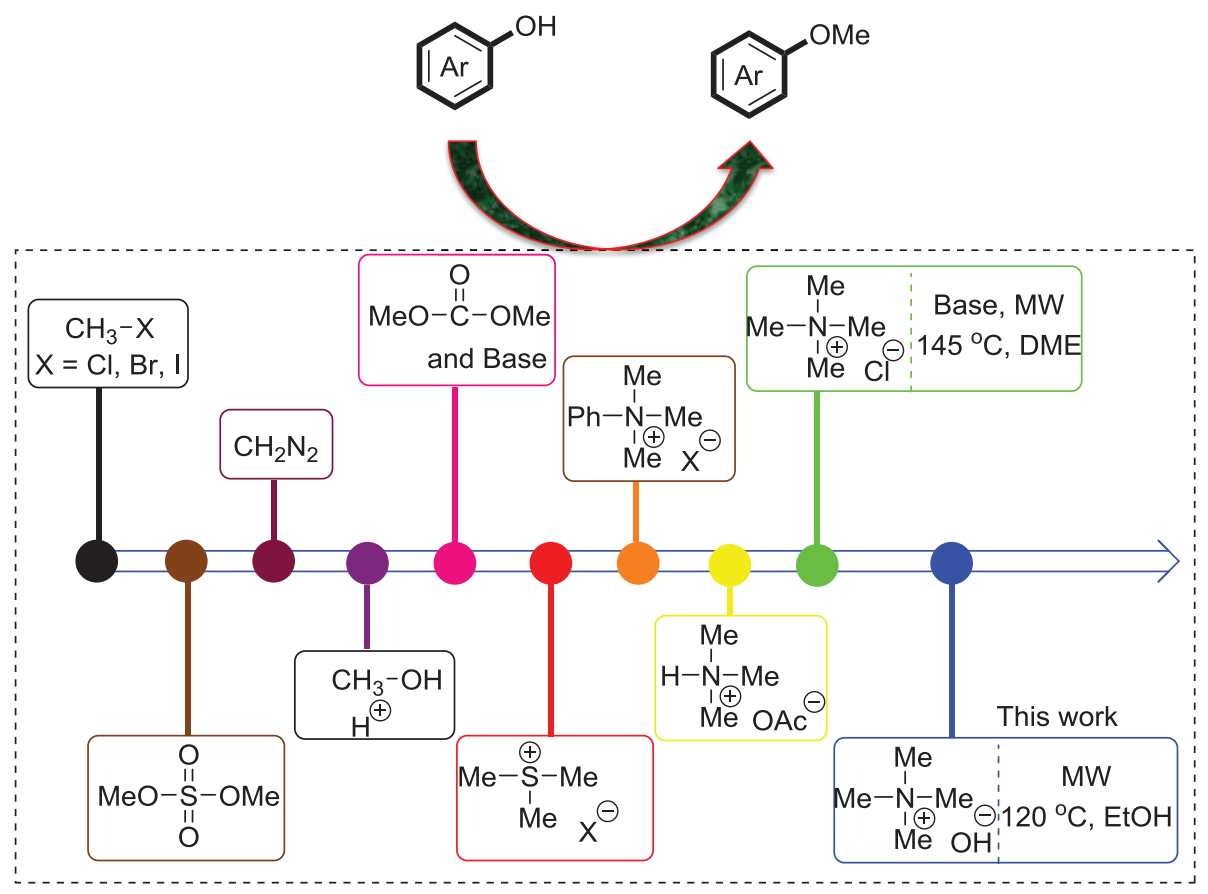

Figure 1: Different methylating agents used for 0-methylation of phenolic compounds. 


\subsection{General procedure for 0-methylation of phenolic compounds using TMAH under MW irradiation}

A mixture of $1 \mathrm{mmol}$ phenol derivates (0.144 gr 2-naphthol, 0.094 gr phenol, $0.173 \mathrm{gr}$ 4-bromophenol, ...) and $1 \mathrm{mmol}$ tetramethylammonium hydroxide (0.34 mL TMAOH 25\%) and $6 \mathrm{~mL}$ ethanol was placed in a sealed teflon container (screw cap type, $50 \mathrm{~mL}$ ) and subjected to microwave irradiation in a microwave oven (Anton Paar 3000) at $120^{\circ} \mathrm{C}$ for $27 \mathrm{~min}$. After cooling, the products were analyzed by GC-MS.

To isolate the product, after completion of the reaction the solvent was removed to obtain a concentrated mixture and ethyl acetate $(20 \mathrm{~mL})$ was added to the reaction mixture and it was washed with water $(2 \times 10 \mathrm{~mL})$. Then the organic layer was dried over $\mathrm{Na}_{2} \mathrm{SO}_{4}$ and after removing solvent the crude product was obtained which purified by column chromatography.

2-Methoxynaphthalene (2a): ${ }^{1} \mathrm{H}$ NMR $(300 \mathrm{MHz}$, $\mathrm{CDCl}_{3}$ ): $\delta$ 7.78-7.55 (m, 1H), 7.41-7.31 (m, 1H), 7.24 (ddd, J = 8.1, 6.9, 1.3 Hz, 1H), 7.09-6.98 (m, 1H), $3.83(\mathrm{~s}, 1 \mathrm{H})$.

Anisole (2K): ${ }^{1} \mathrm{H}$ NMR (300 MHz, $\mathrm{CDCl}_{3}$ ): $\delta$ 7.32-7.08 (m, 1H), 6.93-6.68 (m, 1H), 3.68 (s, 2H).

\section{Results and discussion}

In order to find optimized conditions for our protocol, a reaction model was selected and different reaction conditions were checked (Table 1).

First, we checked the reaction in water as a green solvent and no product was observed (Table 1, entry1). Also, no product was detected using glycerol as solvent (Table 1 , entry 2). Interestingly, in ethanol solvent about $70 \%$ of 2-methoxynaphthalene (Figure 2a) was produced (Table 1, entry 3). Other solvents including dimethylformamide (DMF) and tetrahydrofuran (THF) were checked and no superiority related ethanol was observed thus ethanol was selected as solvent for our protocol (Table 1, entries 4 and 5). Then, the reaction time to obtain maximum yield of product was changed and 27 min was sufficient for high conversion (Table 1, entries 6-8). Temperature was other parameter which we investigated and $120^{\circ} \mathrm{C}$ as optimal temperature was selected. The optimized condition for conversion of 2-naphtol to 2-methoxynaphthalene using TMAH as a new methylating agent was selected as entry 3 of Table 1.

After optimization study in order to show the generality of this process in methylation of other substrates several
Table 1: Optimization of reaction condition. ${ }^{\mathrm{a}}$

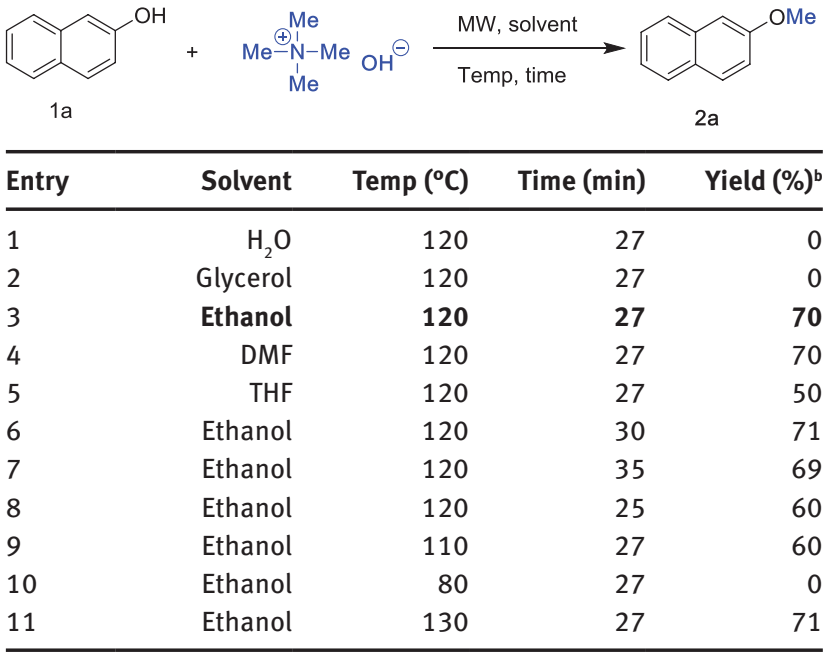

a Reaction condition: 2-naphtol (1 mmol), TMAH (1 mmol), solvent $(6 \mathrm{~mL})$.

${ }^{\mathrm{b}} \mathrm{GC}$ yield.

phenolic compounds containing different functional groups were checked and results are given in Figure 2.

Results in Figure 2 show that different phenolic compounds bearing both electron-withdrawing and electron-donating groups can O-methylated effectively using TMAH under our optimized conditions. O-Methylation of 1-naphtol gave corresponding product in $83 \%$ yield (Figure $2 \mathrm{~b}$ ). Good yields of products from O-methylation of nitro-phenols were obtained (Figures 2c and 2d). Also, halogen-substituted phenols undergo in the reaction and give satisfactory yields of corresponding ethers (Figures 2e-g). Both hydroxyl group of pyrocatechol effectively methylated under optimized conditions and $64 \%$ of 1,2-dimethoxybenzene was produced (Figure $2 \mathrm{~h}$ ). An acceptable yield of product was obtained from 4-benzylphenol using TMAH reagent under MW conditions (Figure 2i). 2,6-Dimethylphenol as a sterically hindered reagent was used and interestingly $88 \%$ yield of 2-methoxy-1,3-dimethylbenzene (Figure 2j) was detected. Using this methodology it is possible to convert phenol to anisole (Figure $2 \mathrm{k}$ ) as a solvent in organic chemistry in high yield of 91\%. Pyridin-4-ol as a heterocyclic phenol (Figure 2l) was employed in this protocol to evaluate its efficiency in synthesis of heterocyclic methyl ethers. The tolerance of cyano, aldehyde and ester functional groups related to the optimized reaction conditions was also checked and corresponding anisoles were produced in high yields without any change in molecular functionality (Figures $2 \mathrm{~m}-\mathrm{o}$ ). Overall, this method is very useful 


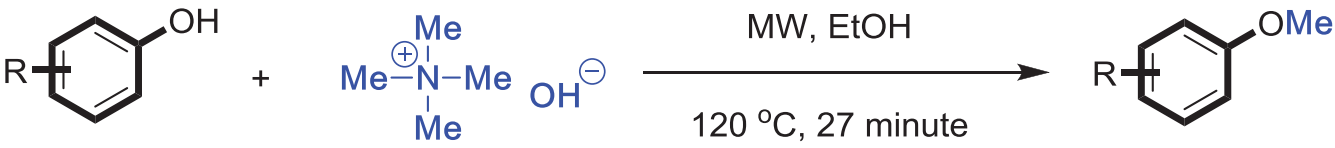

$2 a-2 o$

OMe

2a: $70 \%(66 \%)^{c}$<smiles>COc1cccc2ccccc12</smiles>

2b: $83 \%$<smiles>COc1ccc([N+](=O)[O-])cc1</smiles>

2c: $95 \%$<smiles>COc1cccc([N+](=O)[O-])c1</smiles>

2d: $91 \%$<smiles>COc1ccc(Br)cc1</smiles>

2e: $99 \%$<smiles>COc1ccc(Cl)cc1</smiles>

2f: $98 \%$<smiles>COc1ccc(Cl)cc1Cl</smiles>

$2 \mathrm{~g}: 90 \%$<smiles>COc1ccccc1OC</smiles>

2h: $64 \%$

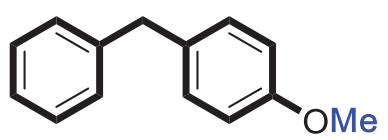

2i: $71 \%$<smiles>COc1c(C)cccc1C</smiles><smiles>COc1ccccc1</smiles><smiles>COc1ccncc1</smiles>

$2 \mathrm{k}: 91 \%(85 \%)^{\mathrm{c}}$<smiles>CC#CCCCCCC</smiles>

2m: $90 \%$<smiles>COc1ccc(C=O)cc1</smiles>

2n: $89 \%$
2I: $75 \%$<smiles>COc1ccc(C(C)=O)cc1</smiles>

2o: $91 \%$

Figure 2: Products of 0 -methylation of different phenolic compounds using TMAH reagent under MW irradiation. ${ }^{\text {a) }}$ Reaction conditions: phenolic compound (1 mmol), TMAH (1 mmol), solvent $(6 \mathrm{~mL})$. b) All yields refer to $\mathrm{GC}$ yield. ${ }^{\mathrm{c}}{ }^{\text {I I }}$ Isolated yields.

and practical for selective O-methylation of phenolic compounds in order to synthesis diverse anisole derivatives quickly.

In view point of reaction mechanism (Figure 3), it seems that, phenolic compound in the presence of TMAH lose a proton so it converted to a phenoxide ion with counter ion of tetramethylammonium ion. In this situation, under reaction conditions phenoxide attack to one the methyl group of tetramethylammonium to afford the O-methylated product.
As observable in Figure 3 the byproducts of this reaction are water and trimethylamine. Because trimethylamine is soluble in water to concentration of $40 \%$ in equilibrium with TMAH, this unpleasant smelling compound is trapped and the bad smell of this byproduct is not feeling after completion of reaction at room temperature.

In order to show the merit and applicability of this new methodology in O-methylation of phenolic compounds a table of comparison was provided. Table 2 demonstrates 


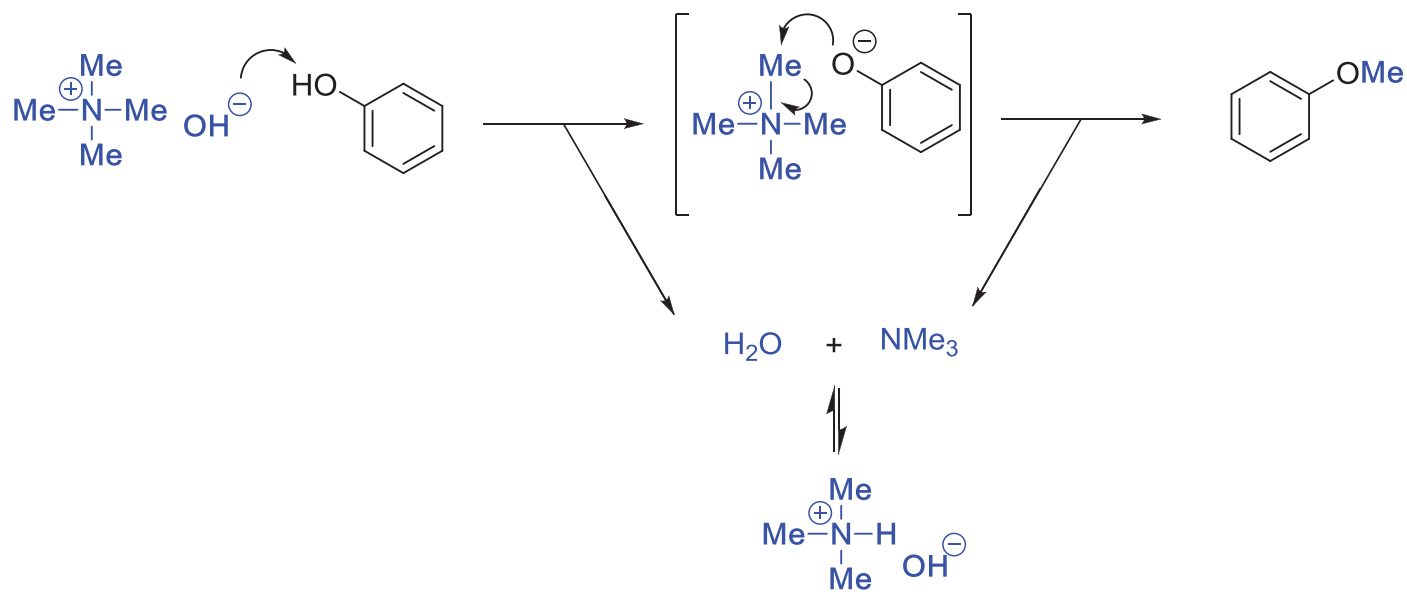

Figure 3: The reaction mechanism of methylation of phenolic component in the presence of TMAH.

Table 2: Different methods for 0-methylation of phenolic compounds.

\begin{tabular}{|c|c|c|c|c|c|c|}
\hline Methylating Agent & Base & Solvent & Solid Catalyst & $\begin{array}{r}\text { Temperature } \\
\left({ }^{\circ} \mathrm{C}\right)\end{array}$ & Yield & Ref. \\
\hline Methyl iodide & $\mathrm{KOH}$ & DMSO & - & 55 & 85 & [3] \\
\hline Methyl bromide & $\mathrm{KOH}$ & DMSO & - & 55 & 73 & [3] \\
\hline Dimethyl sulfate & $\mathrm{NaOH}$ & Water & - & 100 & 47 & [4] \\
\hline Dimethyl sulfate & $\mathrm{KOH}$ & - & $\begin{array}{r}\text { Zeolite } \\
\text { Silica gel }\end{array}$ & & 56 & [1] \\
\hline Dimethyl sulfate & - & Cyclohexane & Alumina & 30 & 36 & [5] \\
\hline Diazomethane & - & - & Silica gel & 30 & 99 & [7] \\
\hline Methanol & $\mathrm{KOH}$ & $\mathrm{H}_{2} \mathrm{SO}_{4}$ & Alumina & 260 & 78 & [10] \\
\hline Methanol & - & $\begin{array}{rl}2 & 4 \\
- & \end{array}$ & $\mathrm{Cs} / \mathrm{SiO}_{2}$ & 400 & 92 & [11] \\
\hline Methanol & - & - & Zeolite Y & 200 & 15 & [12] \\
\hline Dimethyl carbonate & - & - & ZSM5 & 200 & 26 & [19] \\
\hline Dimethyl carbonate & - & {$[\mathrm{BMIm}] \mathrm{Cl}$} & - & 120 & 99 & [23] \\
\hline Dimethyl carbonate & - & - & $\mathrm{Mg} / \mathrm{Al}$ oxide & 200 & 99 & [26] \\
\hline Trialkylsulfonium salt & $\mathrm{K}_{2} \mathrm{CO}_{3}$ & $\begin{array}{r}\mathrm{CH}_{2} \mathrm{Cl}_{2} \\
\text { Acetone }\end{array}$ & - & 30 & $\begin{array}{l}55 \\
82\end{array}$ & [28] \\
\hline Tetramethyl ammonium chloride & $\begin{array}{r}\mathrm{K}_{2} \mathrm{CO}_{3} \\
\mathrm{Cs}_{2} \mathrm{CO}_{3}\end{array}$ & Dimethoxy ethane & - & 145 & 87 & [29] \\
\hline TMAH & - & Ethanol & - & 120 & 91 & This work \\
\hline
\end{tabular}

that this developed procedure has some modifications in view pints of reaction yields and conditions compared to previous reports.

\section{Conclusion}

In conclusion, we have illustrated a novel protocol for efficient and selective O-methylations of phenolic compounds to evaluate the potential of TMAOH as a new methylating agent. Using this methodology phenolic compounds can be converted to aryl methyl derivatives in high yields. This procedure was accomplished in ethanol as a green solvent and under microwave irradiation. The side products of this reaction are trimethylamine and water which can be recovered from the reaction. TMAOH can be used successfully as methylating agent for O-methylation of various phenols and naphthols.

\section{References}

[1] Heravi M.M., Ahari N.Z., Oskooie H.A., Ghassemzadeh M. Solid State S-Methylation of Thiols and O-Methylation of Phenols and Naphthols with Dimethyl Sulfate Under Microwave Irradiation. Phosphorus Sulfur, 2005, 180, 1701-1712. 
[2] Gilman H., Beaber N.J., The Alkylation of Mercaptans by Means of Sulfonic Esters. J. Am. Chem. Soc., 1925, 47, 1449-1451.

[3] Johnstone R.A.W., Rose M.E., A rapid, simple, and mild procedure for alkylation of phenols, alcohols, amides and acids. Tetrahedron, 1979, 35, 2169-2173.

[4] Lewis H.F., Shaffer S., Trieschmann W., Cogan H., Methylation of Phenol by Dimethyl Sulfate. Ind. Eng. Chem. Res., 1930, 22, 34-36.

[5] Ogawa H., Ichimura Y., Chihara T., Terarani S., Taya K., Methylation of alcohols, phenols and carboxylic acid and selective monomethylation og diols and dicarboxylic acidx with dimethyl sulfate by use of alumina. Chem. Soc. Jap., 1986, 59, 2481-2483.

[6] Jursic B., Bregant N., The Selective Methylation of 4-Ethoxycarbonyl-3-Methylpyrazolin-5-One with Dimethyl Sulfate. Synth. Commun., 2006, 19, 2087-2093.

[7] Ogawa H., Hagiwara T., Chihara T., Teratani S., Taya K., Methylation of alcohols and phenols adsorbed on silica Gel with diazomethane. Chem. Soc. Jap., 1987, 60, 34-38.

[8] Bolt H.M., Gansewendt B., Mechanisms of Carcinogenicity of Methyl Halides. Crit. Rev. Toxicol., 1993, 23, 237-253.

[9] Bitter I., Csokai V., An expedient route to p-tert-butylthiacalix[4] arene 1,3-diethers via Mitsunobu reactions. Tetrahedron Lett., 2003, 44, 2261-2265.

[10] Samolada M.C., Grigoriadou E., Kiparisides Z., Vasalos I.A., Selective 0-alkylation of phenol with methanol over sulphates supported on $\mathrm{Al}_{2} \mathrm{O}_{3}$. J. Catal., 1994, 152, 52-56.

[11] Ballarini N., Cavani F., Maselli L.A., The transformations involving methanol in the acid- and base-catalyzed gas-phase methylation of phenol. J. Catal., 2007, 251, 423-436.

[12] Marczewski M., Bodibo J.P., Perot G., Guisnet M., Alkylation of aromatics part i. reaction network of the alkylation of phenol by methanol on ushy zeolite. J. Mol. Catal., 1989, 50, 211-218.

[13] Pierantozzi R., Nordquist A.F., Selective 0-alkylation of phenol with methanol. Appl. Catal. A, 1986, 21, 263-271.

[14] Subramanian T., Dhakshinamoorthy A., Pitchumani K., Amino acid intercalated layered double hydroxide catalyzed chemoselective methylation of phenols and thiophenols with dimethyl carbonate. Tetrahedron Lett., 2013, 54, 7176-7170.

[15] Tundo P., Selva M., The chemistry of dimethyl carbonate. J. Am. Chem. Soc., 2002, 35, 706-716.

[16] Tundo P., Moraglio G. Trotta F., Gas-liquid phase-transfer catalysis: a new continuous-flow method in organic synthesis. Ind. Eng. Chem. Res., 1989, 28, 881-890.

[17] Tundo P., Trotta F., Moraglio G., Ligorati F., Continuous-flow processes under gas-liquid phase-transfer catalysis (GL-PTC) conditions: the reaction of dialkyl carbonates with phenols, alcohols, and mercaptans. Ind. Eng. Chem. Res., 1988, 27, 1565-1571.
[18] Bomben A., Selva M., Tundo P., Continuous-flow o-methylation of phenols with dimethyl carbonate in a continuously fed stirred tank reactor. Ind. Eng. Chem. Res., 1999, 38, 2075-2079.

[19] Fu Z.H., Ono Y., Selective O-methylation of phenol with dimethyl carbonate over X-zeolites. Catal. Lett., 1993, 21, 43-47.

[20] Beutel T., Spectroscopic and kinetic study of the alkylation of phenol with dimethyl carbonate over NaX zeolite. J. Chem. Soc., 1998, 94, 985-993.

[21] Kirumakki S.R., Nagaraju N., Chary K.V.R., Narayanan S., A facile o-alkylation of 2-naphthol over zeolites $\mathrm{H} \beta$, HY, and HZSM5 using dimethyl carbonate and methanol. J. Catal., 2004, 221, 549-559.

[22] Romero M.D, Ovejero G., Rodríguez A., Gomez J.M., Agueda I., O-methylation of phenol in liquid phase over basic zeolites. Ind. Eng. Chem. Res., 2004, 43, 8194-8199.

[23] Shen Z.L., Jiang X.Z., Mo W.M., Hua B.X., Suna N., Catalytic 0-methylation of phenols with dimethyl carbonate to aryl methyl ethers using $[\mathrm{BMIm}] \mathrm{Cl}$. Green Chem., 2005, 7, 97-99.

[24] Kabra S.K., Huuhtanen M., Keiski R.L., Yadav G.D., Selectivity engineering of 0 -methylation of hydroxybenzenes with dimethyl carbonate using ionic liquid as catalyst. Reaction Chemistry \& Engineering, 2016, 1, 330-339.

[25] Ouk S., Thiebaud S., Borredona E., Garsb P.L., Dimethyl carbonate and phenols to alkyl aryl ethers via clean synthesis. Green Chem., 2002, 4, 431-435.

[26] Gadge S.T., Mishra A., Gajengi A.L., Shahia N.V., Bhanage B.M., Magnesium oxide as a heterogeneous and recyclable base for the $\mathrm{N}$-methylation of indole and $\mathrm{O}$ methylation of phenol using dimethyl carbonate as a green methylating agent. RSC Adv., 2014, 4, 50271-50276.

[27] Wu G., Wang X., Chen B., Li J., Zhao N., Wei W., et al., Fluorinemodified mesoporous Mg-Al mixed oxides: Mild and stable base catalysts for 0-methylation of phenol with dimethyl carbonate. Appl. Catal. A, 2007, 329, 106-111.

[28] Umemura K., Matsuyama H., Kamigata N., Alkylation of several nucleophiles with alkylsulfonium salts. Chem. Soc. Jap., 1990, 63, 2593-2600.

[29] Maras N., Polanc S., Kocevar M., Microwave-assisted methylation of phenols with tetramethylammonium chloride in the presence of $\mathrm{K}_{2} \mathrm{CO}_{3}$ or $\mathrm{Cs}_{2} \mathrm{CO}_{3}$. Tetrahedron, 2008, 64, 11618-11624.

[30] Huang W.J., Chen C.H., Singh O.V., Lee S.L., Lee S.S., A facile method for the synthesis of glaucine and norglaucine from boldine. Synth. Commun., 2002, 32, 3681-3686.

[31] Wittmann H., Moller G., Ziegler E., Uber reaktionen mit Betain. Monatshefte fur Chemie und verwandte Teile anderer Wissenschaften, 1966, 97, 1207-1216.

[32] Saidi M.R., Rajabi F., A new protocol for o-methylation of phenolic compounds with trimethyl phosphite or trimethyl phosphate under solvent-free condition and microwave irradiation. Phosphoru Sulfur, 2003, 178, 2343-2348. 